\title{
Congenital long-QT syndrome in type 1 diabetes: a unique association
}

\author{
Erdal Kurnaz ${ }^{1}$, Şenay Savaş Erdeve ${ }^{1}$, Senem Özgür ${ }^{2}$, Melikşah Keskin ${ }^{1}$, Pınar Özbudak \\ Semra Çetinkaya ${ }^{1}$, Zehra Aycan ${ }^{1}$ \\ ${ }^{1}$ Pediatric Endocrinology Clinic and ${ }^{2}$ Pediatric Cardiology Clinic, Dr. Sami Ulus Obstetrics and Gynecology and Pediatrics \\ Training and Research Hospital, Ankara, Turkey. E-mail: erdalkurnaz44@gmail.com
}

Received: 12th July 2017, Revised: 24th August 2017, Accepted: 4th November 2018

SUMMARY: Kurnaz E, Savaş Erdeve Ş, Özgür S, Keskin M, Özbudak P, Çetinkaya S, Aycan Z. Congenital long-QT syndrome in type 1 diabetes: a unique association. Turk J Pediatr 2019; 61: 791-793.

In contrast to acquired long QT syndrome (LQTS), congenital LQTS is a relatively rare channelopathy with an incidence of $1 / 2,500$. We describe a patient found to have a prolonged QTc in the setting of newly diagnosed Type $1 \mathrm{DM}$. To the best of our knowledge, this unique association has not been previously reported. Currently, it is shown that glucose ingestion aggravated cardiac repolarization disturbances in LQT2 patients and prolonged the cardiac repolarization phase in healthy controls. Our case presented to the hospital with syncope after increased glucose level. Therefore, it seems that increased glucose level may have prolonged QTc interval and aggravated cardiac repolarization disturbances in the presented case. By this report, we want to emphasize the importance of hyperglycaemia in congenital LQTS.

Key words: diabetes, long $Q T$, cardiac arrhythmias.

Cardiac ion channels, including potassium, are crucial for transporting ions across cell membranes, resulting in cardiac depolarization and repolarization. Voltage-gated potassium $\left(\mathrm{K}_{\mathrm{v}}\right)$ channels are known for their relation to malignant cardiac arrhythmias, where blocked or nonfunctional $\mathrm{K}_{\mathrm{v}}$ channels cause long QT syndrome (LQTS) because of impaired cardiac repolarization.1 Patients with this syndrome have a susceptibility for cardiac arrest and sudden death secondary to the development of polymorphic ventricular tachycardia or torsades de pointes. ${ }^{1}$

Long-QT syndrome can either be acquired or congenital. Although the association between acquired LQTS and medications, electrolyte abnormalities, and endocrinopathies have been widely recognized, congenital LQTS is a relatively rare channelopathy with an incidence of $1 / 2,500 .^{2}$ It is classified numerically as LQT1 to LQT13 according to various sites of mutation in the gene loci. ${ }^{1,2}$ Voltage-gated potassium channels also play a role in glucagon and insulin secretion from the pancreatic $\alpha$ and $\beta$ cells, which are crucial for glucose regulation. ${ }^{3}$

We describe a patient found to have a prolonged QTC in the setting of newly diagnosed Type 1 diabetes mellitus (DM). The patient's QTC interval didn't improve with insulin replacement, and at genetic testing, she was found to have a mutation in the gene for LQTS type 2. Congenital LQTS has not been previously reported to occur in association with Type $1 \mathrm{DM}$. We aimed to present this unique coexistence of congenital Long-QT Syndrome and Type 1 Diabetes because hyperglycaemia may have aggravated cardiac repolarization disturbances in the presented case.

\section{Case Report}

A 14-year-old female presented with symptoms of drinking a lot of water and frequent urination. She had experienced transient loss of consciousness for 15-20 minutes with no contractions or urinary and fecal incontinence 
right before her presentation to an external center. Her personal history revealed no chronic disease, drug use or syncope, but she has suffered from polyuria, polydipsia, body weight loss for more than one month. The patient's tests performed at the external center revealed a blood sugar of $688 \mathrm{mg} / \mathrm{dl}$, blood gas $\mathrm{pH} 7.36, \mathrm{HCO}_{3}: 21.6 \mathrm{mmol} / \mathrm{L}$, and urine ketone: ++ . She had been started on $10 \mathrm{cc} /$ $\mathrm{kg}$ normal saline per hour and referred to our hospital.

She was conscious and in moderate general condition with no acidotic respiration on presentation to the hospital. The height was $151 \mathrm{~cm}$ (1.63 SDS), body weight $30 \mathrm{~kg}(-4.88$ SDS), body temperature $36.4^{\circ} \mathrm{C}$, apical cardiac pulse $108 / \mathrm{min}$, and respiratory rate $30 / \mathrm{min}$. Other system examination findings were normal. Laboratory evaluation revealed $\mathrm{Hb}$ : $14.8 \mathrm{~g} / \mathrm{dL}$, Hct: $38.9 \%$, WBC: $13850 / \mathrm{mm}^{3}$, Platelet: $257.000 / \mathrm{mm}^{3}$, glucose: $414 \mathrm{mg} /$ dl, BUN: $12 \mathrm{mg} / \mathrm{dl}$, creatinine: $0.68 \mathrm{mg} / \mathrm{dl}$, sodium: $135 \mathrm{mEq} / \mathrm{L}$ (135-143), corrected $\mathrm{Na}$ : $140 \mathrm{mEq} / \mathrm{L}$, potassium: $3.4 \mathrm{mEq} / \mathrm{L}$ (3.1-5.5), calcium: $8.9 \mathrm{mg} / \mathrm{dl}$ (8.4-10.2), phosphorus: $3.4 \mathrm{mg} / \mathrm{dl}$ (2.7-4.5), magnesium: $0.79 \mathrm{mmol}$ /L (0.7-0.86 ), AST: $15 \mathrm{U} / \mathrm{L}$, ALT: $17 \mathrm{U} / \mathrm{L}$, creatine kinase: 51 IU/L (28-170), CK-MB: 27 $\mathrm{U} / \mathrm{L}(<25)$, blood gas, $\mathrm{pH}: 7.37, \mathrm{HCO}_{3}: 19.6$ $\mathrm{mmol} / \mathrm{L}$ (18-23), urine ketone: + ,HbAlc: $14.8 \%$ (4.6-6.2), C-peptide: $0.45 \mathrm{ng} / \mathrm{ml}$ (0.94), Islet Antibody: Negative, Anti insulin antibody: $3.28 \%(0-7 \%)$, and Anti GAD: Positive. The patient was diagnosed with autoimmune Type 1 diabetes mellitus and started on subcutaneous insulin therapy at a dose of 1 unit $/ \mathrm{kg} /$ day in 4 doses. Tests for autoimmune diseases that can accompany Type 1 diabetes such as Hashimoto thyroiditis and celiac disease were negative. Thyroid function tests revealed that the patient was euthyroid.

The case was the evaluated for syncope. There was no electrolyte disorder that could cause syncope. The electrocardiogram (ECG) revealed a normal axis, PR range: $0.16 \mathrm{sec}$ $(0.12-0.20 \mathrm{sec})$, QRS range: $0.06 \mathrm{sec}(<0.12)$ (normal) and QTc range: $0.47 \mathrm{sec}(<0.45 \mathrm{sec})$ (long) (Fig. 1). QTc duration increased up to 49.6 seconds during holter monitorization and fluctuations were seen in QTc durations. Family history revealed a diagnosis of long $\mathrm{T}$ syndrome in her father who was therefore

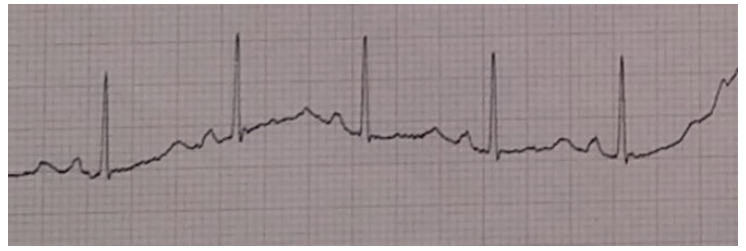

Fig. 1. Electrocardiography was obtained at a paper speed of $25 \mathrm{~mm} / \mathrm{s}$ and an amplitude of $10 \mathrm{~mm} /$ $\mathrm{mV}$. Heart-rate corrected QT, ECG derivation II, is approximately $0,52 \mathrm{sec}$.

using propranolol. QTc duration continued to be $>0.45$ seconds during the 3 weeks of hospitalization. Blood sugar regulation was provided with intensive insulin therapy. The patient was started on $\beta$-blocker therapy by the cardiology department. The patient no longer had QT-related symptoms and no syncope during the follow-up under $\beta$-blocker therapy. However, there was no shortening of the QTc duration. A heterogeneous p.S207Afs*9 (c.619_619delA) novel mutation was found in the $\mathrm{KCNH} 2$ gene with genetic analysis, in the patient and her father.

Written informed consent was obtained from the parent and her family.

\section{Discussion}

Mutations in $\mathrm{KCNH} 2$, cause LQTS type 2 (LQT2) because of impaired function of the pore-forming $\alpha$-subunit of the voltagegated Kv11.1 channel, which is a key player of repolarization in cardiac cells. ${ }^{4}$ Currently, Hyltén-Cavallius et al. ${ }^{5}$ showed that increase of plasma glucose affected heart rate and cardiac repolarization in both LQT2 patients and healthy control participants. Another study reported high glucose likely disrupted Kv11.1 channel trafficking. ${ }^{6}$ A former study found that the disturbances were more pronounced in patients with LQT2. ${ }^{5}$ Because LQT2 patients have a prolonged QT interval, they are more vulnerable to further increases in their QT interval than healthy individuals. On the other hand, prolonged QTc has been reported in cases with diabetic ketosis without any electrolyte disorder ${ }^{7,8}$, yet the patient's QTc didn't improve with insulin replacement, and then at genetic testing, she was found to have a mutation in the gene for LQTS Type 2. Final diagnosis was prolonged QTc in the setting of newly diagnosed Type 1 DM. To the best 
of our knowledge, coexistence of congenital Long-QT Syndrome and Type 1 Diabetes has not been previously reported. It seems that the patient with long QTC syndrome became symptomatic due to hyperglycemia and ketosis. Interestingly, both hyperglycaemia and ketosis stimulated syncope, which is one of the most frequent presentations of long LQ syndrome. From our case, it can be interpreted that high glucose levels cause prolonged QTc interval and aggravated cardiac repolarization disturbances in patients with LQT2 syndrome.

Patients with both Type 1 and Type 2 diabetes mellitus experience prolonged QT interval because of a downregulation of Kv11.1 channels. ${ }^{6,9}$ Hence, abnormal QT prolongation in diabetic patients has become an important clinical problem and has attracted increasing attention, because it increases the risk of lethal ventricular arrhythmias. Hyperglycaemia may cause QTc prolongation in type $1 \mathrm{DM}^{10}$, that may exacerbate cardiac repolarization disturbances in patients with LTQ2 syndrome. ${ }^{5}$ So, glucose outside normal values can lead to increased propensity for QT prolongation; and those values may therefore further increase the risk of malignant arrhythmia in patients with longQT syndrome. Hence, it can be implied that hyperglycaemia should be avoided as much as possible such as that presented in the case because of the increased risk of aggravating cardiac repolarization disturbance.

In summary, it seems that increased glucose levels may have prolonged the QTc interval and aggravated cardiac repolarization disturbances in the presented case. By this report, we want to emphasize the importance of hyperglycaemia in congenital LQTS.

\section{REFERENCES}

1. Saprungruang A, Vithessonthi K, La-Orkhun V, Lertsapcharoen P, Khongphatthanayothin A. Clinical presentation and course of long QT syndrome in Thai children. J Arrhythm 2015; 31: 296-301.

2. Kapplinger JD, Tester DJ, Salisbury BA, et al. Spectrum and prevalence of mutations from the first 2,500 consecutive unrelated patients referred for the FAMILION long QT syndrome genetic test. Heart Rhythm 2009; 6: 1297-1303.

3. Mühlbauer E, Bazwinsky I, Wolgast S, Klemenz A, Peschke E. Circadian changes of ether-a-go-gorelated-gene (Erg) potassium channel transcripts in the rat pancreas and beta-cell. Cell Mol Life Sci 2007; 64: 768-780.

4. Hedley PL, Jørgensen P, Schlamowitz S, et al. The genetic basis of long QT and short QT syndromes: a mutation update. Hum Mutat 2009; 30: 1486-1511.

5. Hyltén-Cavallius L, Iepsen EW, Wewer Albrechtsen NJ, et al. Patients with Long-QT syndrome caused by impaired hERG-encoded K(v) 11.1 potassium channel have exaggerated endocrine pancreatic and incretin function associated with reactive hypoglycemia. Circulation 2017; 135: 1705-1719.

6. Shi YQ, Yan M, Liu LR, et al. High glucose represses hERG $\mathrm{K}+$ channel expression through trafficking inhibition. Cell Physiol Biochem 2015; 37: 284-296.

7. Kuppermann N, Park J, Glatter K, Marcin JP, Glaser NS. Prolonged QT interval corrected for heart rate during diabetic ketoacidosis in children. Arch Pediatr Adolesc Med 2008; 162: 544-549.

8. Youssef OI, Farid SM. QTC and QTd in children with type 1 diabetes mellitus during diabetic ketoacidosis. ISRN Pediatr 2012; doi: 10.5402/2012/619107.

9. Zhang $\mathrm{Y}$, Xiao J, Wang $\mathrm{H}$, et al. Restoring depressed HERG $\mathrm{K}+$ channel function as a mechanism for insulin treatment of abnormal QT prolongation and associated arrhythmias in diabetic rabbits. Am J Physiol Heart Circ Physiol 2006; 291: H1446-H1455.

10. Pickham D, Flowers E, Drew BJ. Hyperglycemia is associated with corrected QT prolongation and mortality in acutely ill patients. J Cardiovasc Nurs 2014; 29: 264-270. 